\title{
Rapid analysis of $\beta$-D-glucuronidase activity in water using fully automated technology
}

\author{
J. Koschelnik, W. Vogl, M. Epp \& M. Lackner \\ Research \& Development, Vienna Water Monitoring Solutions, Austria
}

\begin{abstract}
Microbiological cultivation methods estimate the number of bacteria in water samples mainly as an amount of Colony Forming Units in $100 \mathrm{ml}$ (CFU/100ml) or as a Most Probable Number of fecal bacteria in $100 \mathrm{ml}$ (MPN/100ml). The growing amount of molecular methods for specific detection of fecal bacteria allows rapid measurement without the need for cultivation. These methods could determine the presence of specific genetic markers of fecal bacteria in water expressed in Genomic Equivalent Units per $100 \mathrm{ml}$ (GEU/100ml) or Target Sequence Copy (TSC) per $100 \mathrm{ml}$. Analysis of enzymes, such as $\beta$-Dglucuronidase in indicator bacteria have been used for many years to quantify feces-associated contamination, but the measurement parameter which allows the comparison of the obtained results is not clearly defined. In this work we are introducing a novel parameter: enzymatic activity of beta-D-glucuronidase expressed in Modified Fishman Units per $100 \mathrm{ml}$ of water sample (MFU/100ml). A fully automated device to detect enzymatic activity above $0.001 \mathrm{MFU} / 100 \mathrm{ml}$ in freshwater without sample pretreatment within less than 60 minutes was developed and subjected to field tests. The instrument measures enzymatic activity by detection of accumulated reaction product. Due to the short measurement time, the technology can be used both for water quality monitoring purposes and for process control applications.
\end{abstract}

Keywords: E. coli, fecal contamination, water monitoring, enzymatic activity, glucuronidase, modified fishman units, MFU/100ml, ColiMinder.

\section{Introduction}

Water monitoring for microbiological quality is primarily based on test for indicator bacteria. Coliforms and E. coli have traditionally been used as indicators 
based on the assumption that there is a direct relationship between the concentration of indicator bacteria and the potential health risks involved [1]. There is a wide variety of microbiological and biochemical methods available for testing the microbial quality of water through these indicator microorganisms. Microbiological cultivation methods estimate the number of bacteria in water samples, molecular methods allow qualitative and quantitative detection of indicator bacteria without the need for cultivation [2]. These methods are primarily based on the identification of specific genetic markers or antigenic determinants as well as on the measurement of specific metabolic activity in fecal-associated bacteria. Although there is no clear correlation between microbial counts and the number of genomic copies or catalytic activity of specific enzymes in analyzed water samples, the measurement units should be clearly designated. On the one hand, microbiological methods of bacterial enumeration expressed in CFU/100ml or MPN/100ml and the measurement results of genetic markers identification, expressed in $\mathrm{GC} / 100 \mathrm{ml}$ ( $\mathrm{GC}=$ Genome Copies) [3] or CCE/100ml (CCE = Calibrator Cell Equivalent) [4] are already defined and generally accepted. On the other hand, the measurement units for enzymatic activity of $\beta$-D-glucuronidase in fecal indicator bacteria are still not quite suitable for quantitative analysis. The amount of product released by catalytic cleavage of substrate in certain period of time, usually expressed in $\mathrm{pmol} / \mathrm{min} / 100 \mathrm{ml}$ or $\mathrm{nM} / \mathrm{min}$ [5-7], significantly depends on the chosen substrate and the measurement conditions. In this work we are introducing a novel parameter: enzymatic activity of $\beta$-D-glucuronidase expressed in Modified Fishman Units in $100 \mathrm{ml}$ of water sample (MFU/100ml) [8]. This new parameter gives a value which is completely independent on the measurement procedure and therefore is applicable for quantitative comparative studies.

The calibrations, various comparison tests as well as field trial were performed using fully automated device capable to detect enzymatic activity of $\beta$-Dglucuronidase above $0.001 \mathrm{MFU} / 100 \mathrm{ml}$ in freshwater within less than $60 \mathrm{~min}$ without sample pretreatment.

\section{Material and methods}

\subsection{The automated measuring device for monitoring of enzymatic activity}

Activity of $\beta$-D-glucuronidase was analyzed by fully automated fluorescence photometer ColiMinder P06 (VWM, Austria) which is designed for real-time measurement of enzymatic activity in liquid samples. The device performs automated batch processing of liquid samples (6.5 $\mathrm{ml}$ total volume). All measurement and calibration parameters (temperature, duration of assay, volume of buffer, substrate or calibration solutions) can be set manually or remotely using "E-Trace Control" software. The assay protocol for $\beta$-D-glucuronidase activity is based on the fluorescence detection of enzymatic reaction product (4-Methylumbelliferone). The central unit of device is a measurement chamber, where fresh unfiltered water sample is mixed with defined buffer and fluorogenic substrate solution and preheated to the desired temperature (in case of $\beta$-D- 
glucuronidase it is $44 \cdot 0 \pm 0 \cdot 1^{\circ} \mathrm{C}$ ). As soon as the required temperature range is reached, the measurement process starts automatically. Every measurement procedure includes automated cleaning procedure, reagents and water sample dosing, precise temperature control and fluorescence signal detection. The influence of the sample turbidity is auto-eliminated during the measurement process by using patented technology. In automatic mode, the measurement procedure starts immediately one after the other. The minimal duration of full measurement cycle depends on the sample contamination level and lasts from 30 to $60 \mathrm{~min}$, allowing 24 to 48 measurements per day.

As can be seen in Figure 1, the device consists of several functional modules: Fluidic Module, Measurement Unit, Controlling Unit, Power Unit and User Interface Module. Fluidic Module allows precise liquids sampling and reagent dispensing using digitally-controlled pumps/valves/tubing systems.

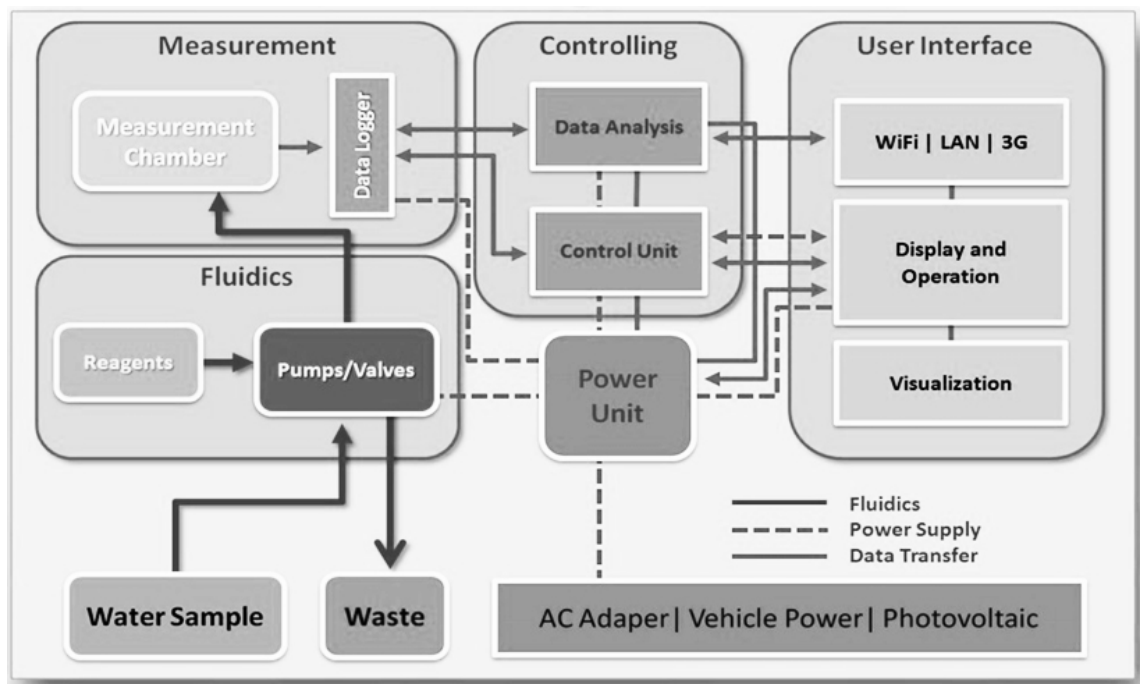

Figure 1: The schematic diagram of ColiMinder P06.

The Measurement Unit detects the signals and generates the raw output data in volts. The Controlling Unit handles all measurement steps and converts the raw output data into defined calibrated values. The User Interface Module allows manual and remote $(\mathrm{LAN} / 3 \mathrm{G} / \mathrm{WiFi})$ control over all measurements steps, provides data transfer, analysis and graphical visualization via web-interface.

The preproduction model of ColiMinder is shown in Figure 2.

The ColiMinder Outdoor Measurement Station (ColiMinder-OMS) contains two identical ColiMinder devices working independently and performs continuous monitoring of enzymatic activity in water samples (Figure 3). 

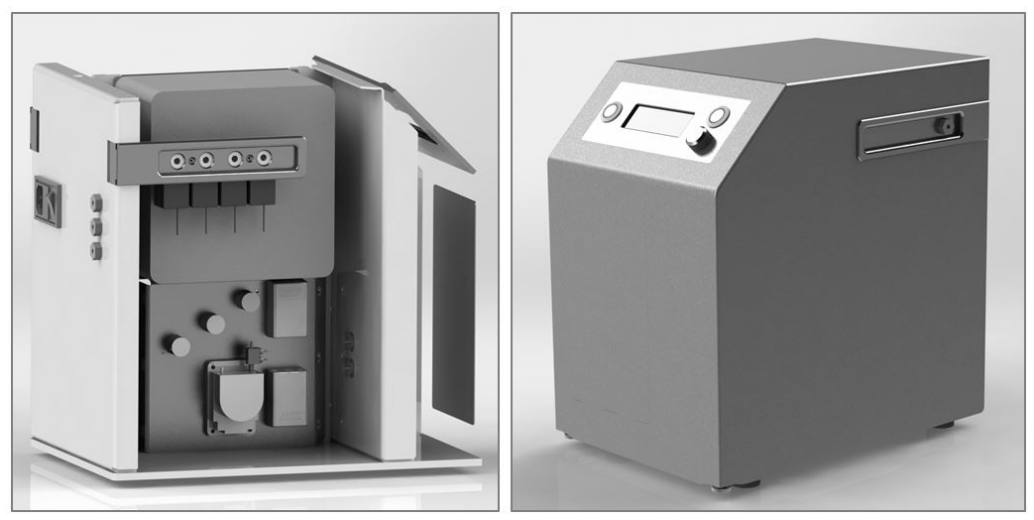

Figure 2: The preproduction model of ColiMinder.

\subsection{Sampling}

Automatic water sampler integrated in outdoor measurement station provides coarsely filtered $(0.9 \mathrm{~mm}$ mesh $)$ fresh water samples for every measurement cycle. Sampling place: HOAL Petzenkirchen (Hydrological Open Air Laboratory, Austria). Creek water samples for conventional microbiological analysis were collected manually, placed in $4^{\circ} \mathrm{C}$ cooling boxes and processed within $6 \mathrm{~h}$ of collection.

\subsection{Measurement of $\beta$-D-glucuronidase activity}

\subsubsection{4-MU calibration}

The intensity of fluorescence signal measured in volts was converted to concentration of fluorophore by calibration with defined 4-methylumbelliferone solutions (4-MU, Sigma-Aldrich, concentration range 0-55 nM).

\subsubsection{MFU calibration}

Enzymatic activity of Type IX-A $\beta$-D-glucuronidase from E. coli (Sigma-Aldrich) was measured in modified "Fishman" units (MFU) according to standard Sigma Quality Control Test Procedure [8] using a Shimadzu spectrophotometer UV-260. Based on the measurements results, the enzyme aliquots containing $0.0005,0.001$, $0.002,0.005,0.01,0.02,0.05$ and $0.2 \mathrm{MFU}$ were prepared and used for calibration.

Calibration solutions of $\beta$-D-glucuronidase ranging from $0.0005 \mathrm{MFU} / 100 \mathrm{ml}$ to $0.2 \mathrm{MFU} / 100 \mathrm{ml}$ were used to convert the slopes of enzymatic reactions $(\mathrm{V} / \mathrm{s})$ measured by ColiMinder P06 device into MFU/100ml. The velocity of enzymatic reaction on the linear phase was determined in buffered assay solution after reaching the constant temperature $\left(44.0 \pm 0.1^{\circ} \mathrm{C}\right)$. Assay buffer contains $50 \mathrm{mM}$ MOPSO, 50mM NaCl, 10mM EDTA, 0.1\% Tween 20, pH 7.3 (all reagents - from Sigma-Aldrich), containing $300 \mu \mathrm{M}$ 4-Methylumbelliferone glucuronides. Highly purified 4-Methylumbelliferone glucuronide was kindly provided by Dr. Hannes Mikula, Vienna Technical University. 


\subsection{Monitoring of bacterial water contamination}

Continuous monitoring of $\beta$-D-glucuronidase activity in creek water with measuring interval of $\sim 45$ min ( 28 measurements per day) is being performed using ColiMinder OMS (Figure 3). The outdoor station contains two identical ColiMinder devices (P06-Alpha and P06-Bravo) and works autonomously since March 2014. All process parameters are remotely controlled; obtained data are synchronized in 2 seconds interval with the central data server. The measurement sensors at HOAL also provide additional physico-chemical parameters (temperature, $\mathrm{pH}$, turbidity, conductivity, $\mathrm{Cl}^{-}, \mathrm{NO}_{3}{ }^{-}$, water level and flow, amount of liquid precipitations).

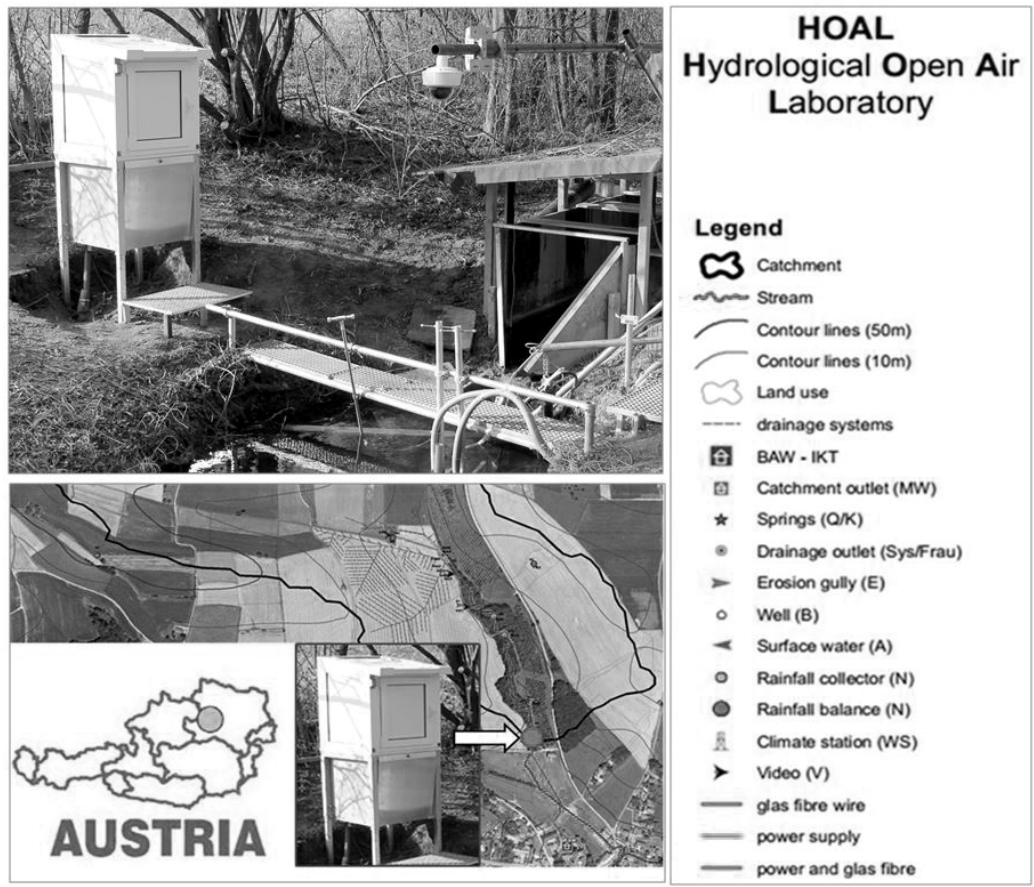

Figure 3: The ColiMinder outdoor measurement station at HOAL.

\section{Results and discussion}

\subsection{Laboratory calibrations}

The quantitative analysis of $\beta$-D-glucuronidase activity by detection of fluorescence level of accumulated reaction product (4-methylumbelliferone) requires several calibration steps. Since accuracy of measurement, as well as the velocity of enzymatic reaction is strongly dependent on the temperature of assay solution, the valid measurement is started after preheating phase by reaching the 
constant temperature (Figure 4). Integrated proportional-integral-derivative (PID) temperature controller with several temperature sensors is tuned for the optimal performance. The influence of sample's optical density on the fluorescence intensity was deducted by calibrations with the set of turbidity standards.

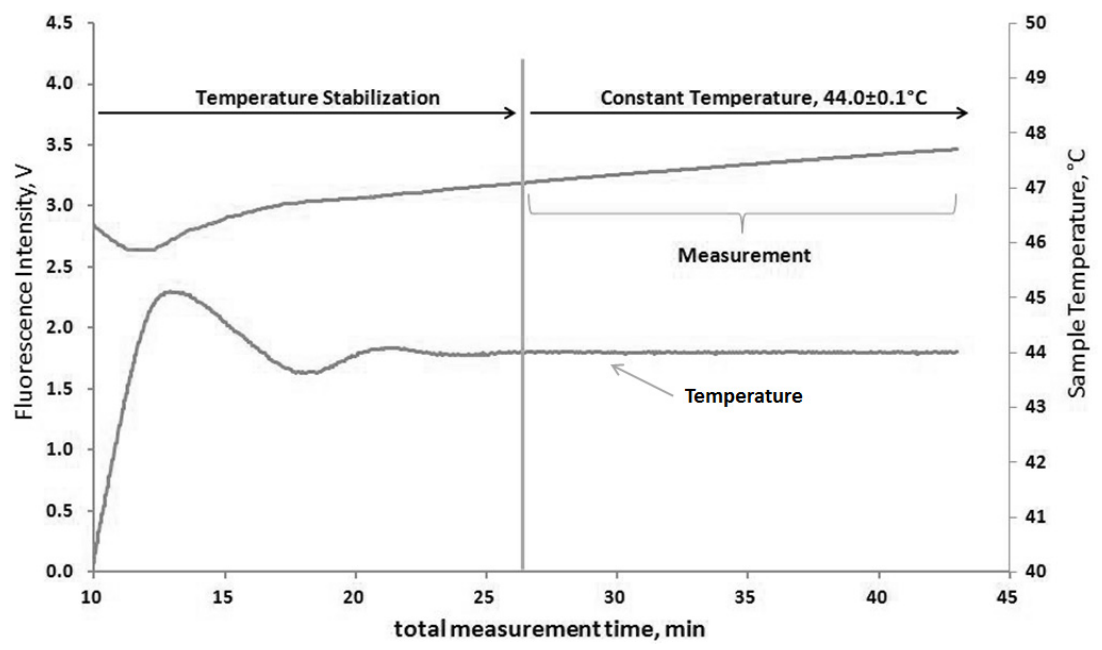

Figure 4: Preheating and measurement phases of $\beta$-D-glucuronidase activity measurement cycle analysed by ColiMinder P06.

In order to convert the relative value of fluorescence intensity measured in volts into absolute value (concentration of 4-MU), the ColiMinder device was autocalibrated with buffered assay solution containing incrementally increased concentrations of 4-MU (from 0 to $55 \mathrm{nM}$, increment step: $3.44 \mathrm{nM}$ ), see Figure 5 (left). To remove traces of fluorescent material from tubing and detection chamber, the full cleaning cycle preceded each measurement step. Calibration curve (Figure 5, right) shows linear relationship between fluorescence signal in volts and the analyzed concentrations of fluorophore.
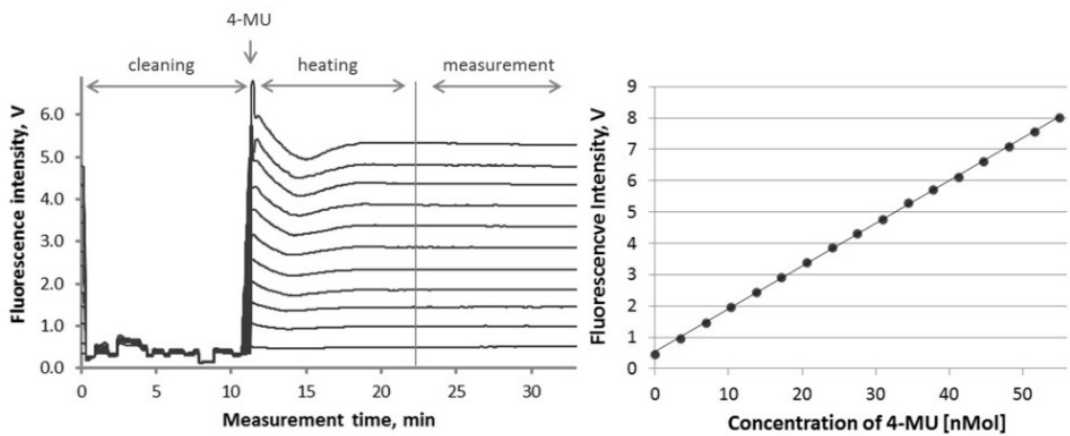

Figure 5: Measurement of fluorescence intensity of assay solutions with incrementally increased concentrations of 4-MU. 
According to standard Sigma Quality Control Test Procedure [8], one modified "Fishman" unit (MFU) of enzymatic activity of $\beta$-D-glucuronidase from E. coli liberates $1.0 \mu \mathrm{g}$ of phenolphthalein from phenolphthalein-glucuronide per hour at $\mathrm{pH} 6.8$ at $37^{\circ} \mathrm{C}$. Reference calibration solutions of $\beta$-D-glucuronidase containing $0.0005,0.001,0.002,0.005,0.01,0.02,0.05$ and $0.2 \mathrm{MFU} / 100 \mathrm{ml}$ were analyzed by ColiMinder P06 (Figure 6). Calibration curve (Figure 6, right) shows linear relationship between the velocity of enzymatic reaction $(\mathrm{nM} / \mathrm{min})$ and given concentrations of enzyme.
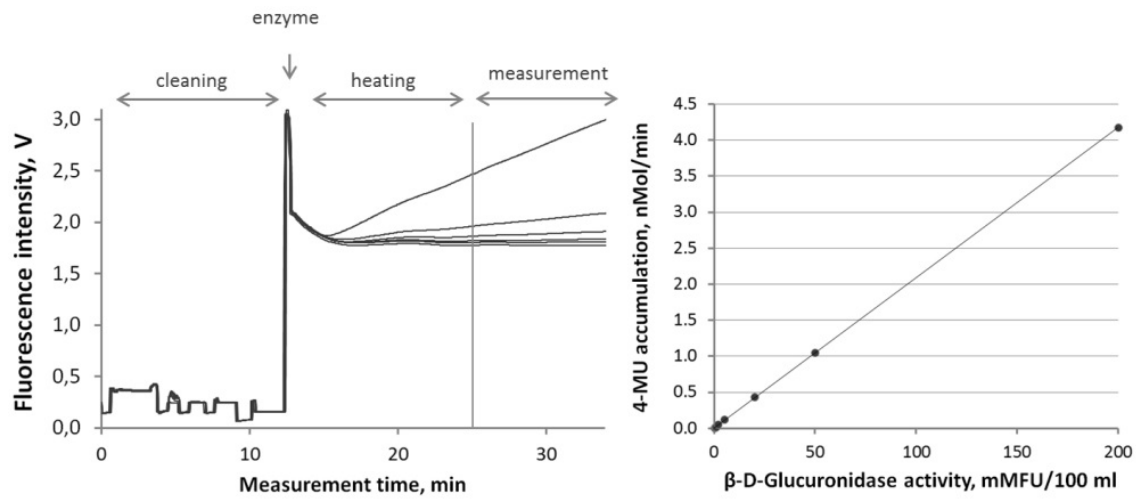

Figure 6: Measurement of reference calibration solutions of $\beta$-D-glucuronidase.

Highly contaminated water sample could produce the signal above the detection limit. Therefore a calibration with higher concentration of enzyme and reduced excitation light intensity was performed. A reference calibration solution of $\beta$-D-glucuronidase containing $0.2 \mathrm{MFU} / 100 \mathrm{ml}$ was analyzed by ColiMinder P06 using light intensity auto-adjustment mode (Figure 7, left). The row data processing using correction protocol is shown on Figure 7 (right).

This method allows detecting the enzymatic activity in a very broad range (from $0.001 \mathrm{MFU} / 100 \mathrm{ml}$ to $1.5 \mathrm{MFU} / 100 \mathrm{ml}$ ).
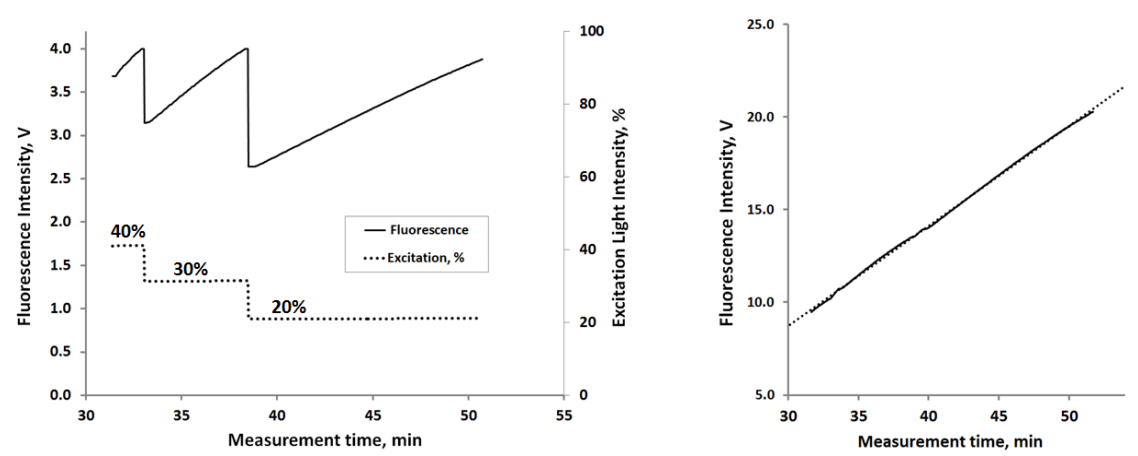

Figure 7: Auto-calibration of $0.2 \mathrm{MFU} / 100 \mathrm{ml} \beta$-D-glucuronidase solution. 
The comparison of standard Sigma Quality Control Test Procedure for $\beta-\mathrm{D}$ glucuronidase enzymatic activity with current ColiMinder-P06 measurement protocol revealed remarkable differences in estimation enzyme activity expressed in $\mathrm{nM} / \mathrm{min}$ (or $\mathrm{pmol} / \mathrm{min} / 100 \mathrm{ml}$ ). According to Sigma assay, the concentration of $\beta$-D-glucuronidase equal to $1 \mathrm{MFU} / 100 \mathrm{ml}$ liberates $0.5236 \mathrm{nM} / \mathrm{min}$ (or 52.36 $\mathrm{pmol} / 100 \mathrm{ml} / \mathrm{min}$ ) of phenolphthalein. Using equal concentration of $\beta$-Dglucuronidase, the ColiMinder measurement technology shows much higher accumulation of 4-MU: $22.94 \mathrm{nM} / \mathrm{min}$ (or $2294 \mathrm{pmol} / 100 \mathrm{ml} / \mathrm{min}$ ). After calibration to MFU/100ml both methods shows identical values for the same enzymatic activity.

Therefore, analysis of $\beta$-D-glucuronidase enzymatic activity in real water samples using $\mathrm{MFU} / 100 \mathrm{ml}$ as a measurement parameter allows comparing obtained results independently on chosen measurement device or assay protocol.

\subsection{Field tests}

ColiMinder Outdoor Measurement Station continuously monitors the activity of $\beta$-D-glucuronidase in creek water located at HOAL Petzenkirchen. For the time period from $17^{\text {th }}$ of March until $6^{\text {th }}$ of May more than 2100 measures were gathered and analyzed. Figure 8 shows the dynamics of $\beta$-D-glucuronidase activity for the whole measurement period. Several striking peaks of enzymatic activity, which were in accordance with environmental events (rainfall, increased discharge and water turbidity), could be observed.

Due to the short measurement time, the ColiMinder technology allows to detect even weak diurnal fluctuations of enzymatic activity. Figure 9 shows an example of measurements data for the short time interval: from 26.03.2014 to 04.04.2014. Both devices (P06-Alpha and P06-Bravo) show accurate and comparable measurement values. The variations in measurement results between the devices reflect the differences in water samples and proximity to the detection limit. The repeated changes of $\beta$-D-glucuronidase enzymatic activity (daytime increase and night time decrease) correlate with the water and air temperature, daylight and water level, but there is no convincing explanation for this phenomenon.

Environmental events show significant influence on the $\beta$-D-glucuronidase activity. The rainfall on $6.04 .2014(10 \mathrm{~mm}$ precipitation between 16:00 and 18:00, Figure 10, left) and the rainfall on 2.05.2014 (9.5 mm precipitation between 18:00 and 24:00, Figure 10, right) evoked 23-fold and 10.2-fold increase of enzymatic activity, compared to basal level.

Microbiological enumeration of E. coli in water samples using IDEXX Colilert tests was performed daily. Basal E. coli level for measurement time from 26.04.2014 to 5.05.2014 lies between 4.2 and 9.7 MPN/100ml. During the rainfall on 2.05.2014, the level of E. coli was measured every 20 min (Table 1).

Although the measurement interval of microbiological analysis does not allow comparing directly the fluctuations of enzymatic activity measured by ColiMinder with corresponding E. coli level measured by cultivation method, in general, bacterial contamination dynamics shows good correlations with enzymatic activity. 


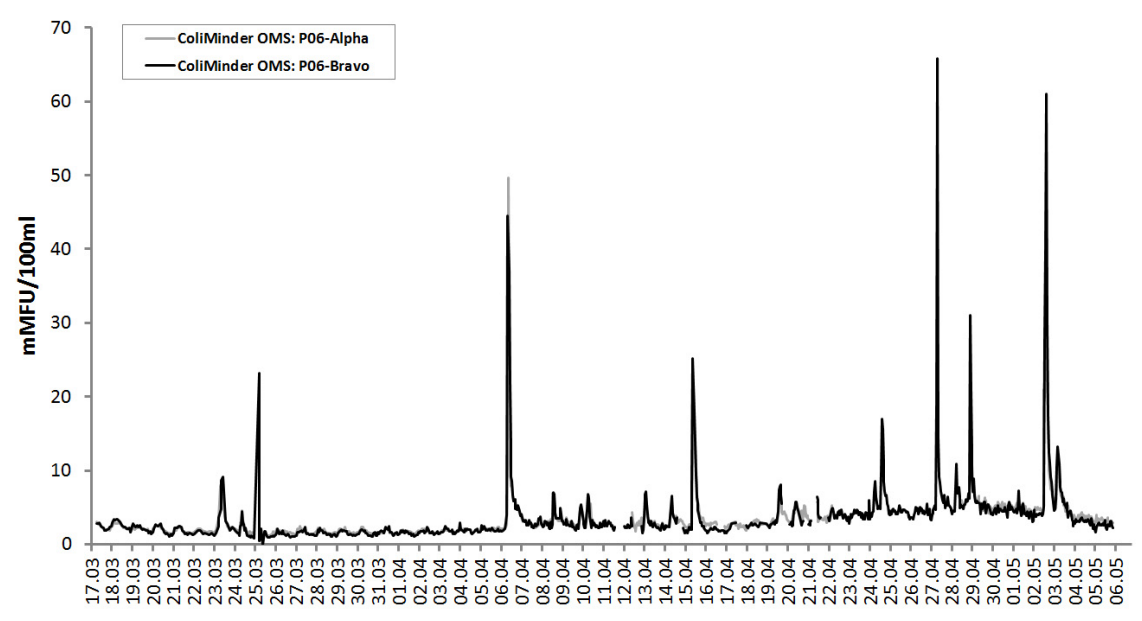

Figure 8: Continuous monitoring of $\beta$-D-glucuronidase activity in creek water.

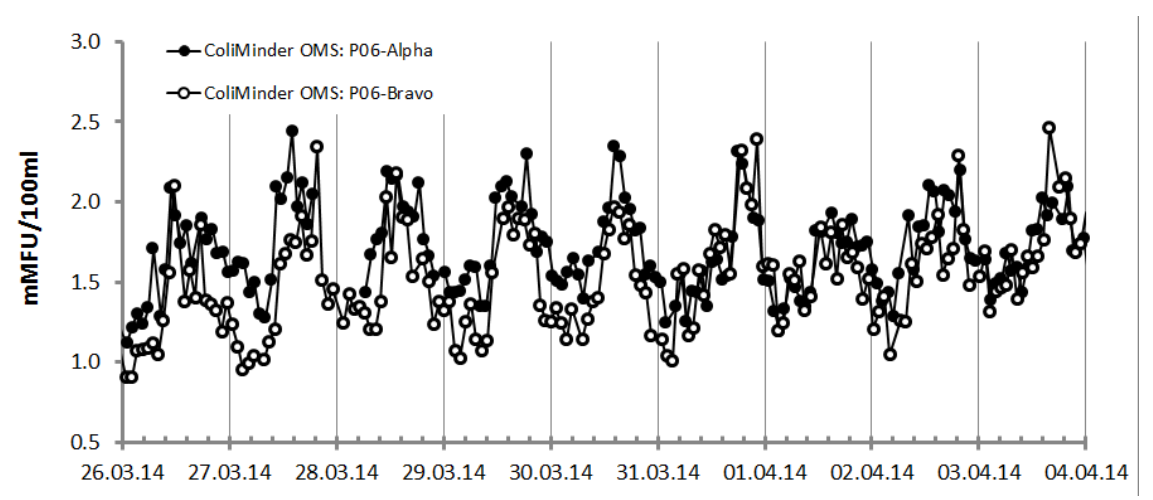

Figure 9: Daily fluctuations of $\beta$-D-glucuronidase activity.
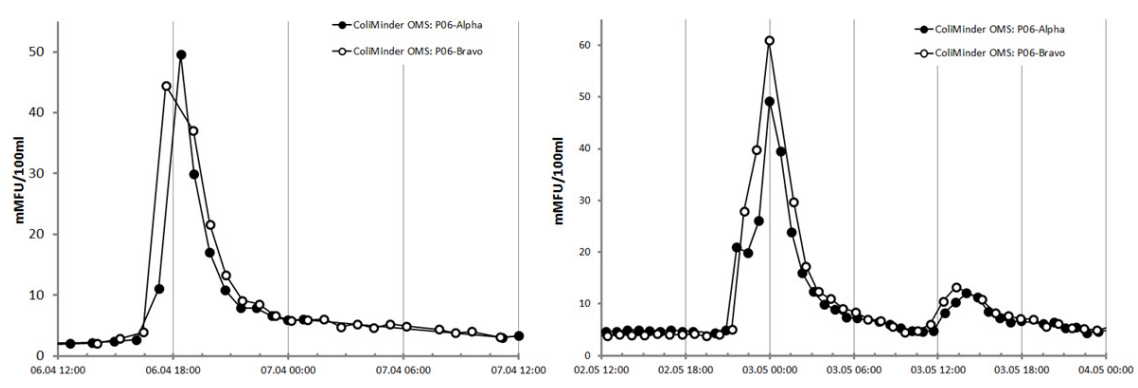

Figure 10: Dynamic of enzymatic activity during environmental events. 
Table 1: Rainfall event on 2.05.2014. Comparison of E. coli enumeration $(\mathrm{MPN} / 100 \mathrm{ml})$ and $\beta$-D-glucuronidase activity (mMFU/100ml).

\begin{tabular}{|c|c|c|}
\hline Date & E. coli, MPN/100ml & Glucuronidase, mMFU/100ml \\
\hline $02.05 .201420: 00$ & 9.7 & \\
\hline $02.05 .201420: 22$ & & 4.09 \\
\hline $02.05 .201422: 20$ & 1413.6 & 20.97 \\
\hline $02.05 .201421: 38$ & & \\
\hline $02.05 .201422: 40$ & 1732.9 & 27.91 \\
\hline $02.05 .201422: 10$ & & \\
\hline $02.05 .201423: 00$ & 1553.1 & 39.77 \\
\hline $02.05 .201423: 03$ & & \\
\hline $02.05 .201423: 20$ & 1732.9 & \\
\hline $02.05 .201423: 40$ & 3129.0 & \\
\hline $02.05 .201423: 56$ & & \\
\hline
\end{tabular}

\section{Conclusions}

Analysis of $\beta$-D-glucuronidase enzymatic activity in real water samples using $\mathrm{MFU} / 100 \mathrm{ml}$ as a measurement parameter allows comparing obtained results regardless of chosen measurement device or assay protocol.

ColiMinder-P06 presented here is a fully automated device to measure $\beta$-Dglucuronidase enzymatic activity in water. The device does not require sample pre-treatment, it uses an improved fluorescence measurement technology that compensates the influence of water turbidity, and therefore suspended particles have no negative effect on the measurement accuracy. ColiMinder produces quick and accurate results in a very broad range of contamination and provides new possibilities in continuous near real-time water quality monitoring.

In preliminary tests fluctuation of fecal contamination could be tracked with a previously impossible time resolution, giving insights into development and abatement of contamination.

\section{Acknowledgements}

This work was funded by the Austrian research agency FFG under grant numbers 841582 and 4161494 and by the Austrian agency AWS under grant numbers P1103892-PSi01 and P1304383-CZi01. The authors want to thank Prof. Dr. Zessner-Spitzenberg from Vienna University of Technology for carrying out field trials with the ColiMinder-OMS in Austria. 


\section{References}

[1] Eaton, A.D., Clesceri, L.S., Greenberg, A.E. \& Franson, M.A.H., Standard Methods for the Examination of Water and Wastewater, American Public Health Association, Washington, DC, 1998.

[2] Field, K.G. \& Samadpour, M., Fecal source tracking, the indicator paradigm, and managing water quality. Water Res 41(16), pp. 3517-3538, 2007.

[3] Shannon, K.E., Lee, D.Y., Trevors, J.T. \& Beaudette, L.A., Application of real-time quantitative PCR for the detection of selected bacterial pathogens during municipal wastewater treatment. Sci Total Environ 382(1), pp. 121129, 2007.

[4] Converse, R.R. et al., Correlation between quantitative PCR and culturebased methods for measuring Enterococcus spp. over various temporal scales at three California marine beaches. Appl Environ Microbiol 78(4), pp. 1237$1242,2012$.

[5] Garcia-Armisen, T., Lebaron, P. \& Servais, P., Beta-D-glucuronidase activity assay to assess viable Escherichia coli abundance in freshwaters. Lett Appl Microbiol 40(4), pp. 278-282, 2005.

[6] Fiksdal, L., Pommepuy, M., Caprais, M.P. \& Midttun, I., Monitoring of fecal pollution in coastal waters by use of rapid enzymatic techniques. Appl Environ Microbiol 60(5), pp. 1581-1584, 1994.

[7] Ryzinska-Paier, G. et al., A sensitive and robust method for automated online monitoring of enzymatic activities in water and water resources. Water Sci Technol 69(6), pp. 1349-1358, 2014.

[8] Sigma-Aldrich, http://www.sigmaaldrich.com/technical-documents/ protocols/biology/enzymatic-assay-of-b-glucuronidase-from-ecoli.html. 